\title{
OS SABERES DA PRÁTICA ALFABETIZADORA CONSTRUÍDOS E MOBILIZADOS NO COTIDIANO DE PROFESSORAS INICIANTES
}

\author{
Me. Joelson de Sousa Morais \\ Universidade Federal do Maranhão (UFMA)
}

Dra. Franc-Lane Sousa Carvalho do Nascimento

Universidade Estadual do Maranhão (UEMA)

RESUMO: O presente trabalho é fruto de um relato de experiência realizada numa pesquisa com três professoras iniciantes, que atuam nos anos iniciais do Ensino Fundamental numa escola do sistema público municipal de CaxiasMA. Primamos como técnicas de investigação as conversas e observações que foram registradas num diário de pesquisa e aparelho de áudio. Tem como objetivo compreender como são mobilizados os saberes da prática alfabetizadora no cotidiano das professoras iniciantes. A perspectiva teóricoepistemológica adotada foram os Estudos do Cotidiano, e para compreender as narrativas das pesquisadas escolhemos a Epistemologia da Complexidade. Os resultados mostraram que as professoras iniciantes, buscam inúmeras táticas e estratégias como forma de contribuir para o processo de alfabetização das crianças, entrelaçando o que sabem com outros saberes provenientes de várias dimensões e contextos de aprendizagem, utilizando da sua criatividade na criação de instrumentos didáticos e pedagógicos, os quais se mostram potencialmente significativas e relevantes para a escolarização dos sujeitos aprendentes.

PALAVRAS-CHAVE: saberes docentes; professoras iniciantes; prática pedagógica alfabetizadora

\section{THE KNOWLEDGE OF LITERACY PRACTICE CONSTRUCTED AND MOBILIZED IN THE DAILY TEACHERS}

\begin{abstract}
The present work is the result of an experience report carried out in a research with three beginning teachers, who work in the initial years of Elementary School in a school of the municipal public system of Caxias-MA. As research techniques, we use the conversations and observations that were recorded in a research diary and audio device. It aims to understand how the knowledge of the literacy practice is mobilized in the daily life of the beginning teachers. The theoreticalepistemological perspective adopted was the
\end{abstract}

Studies of Daily Life, and to understand the narratives of those surveyed, we chose the Epistemology of Complexity. The results showed that the beginning teachers seek numerous tactics and strategies as a way to contribute to the children's literacy process, intertwining what they know with other knowledge from different dimensions and contexts of learning, using their creativity in the creation of didactic tools and pedagogical, which are potentially significant and relevant to the schooling of the learning subjects.

KEYWORDS: teaching knowledges; beginners teachers; literacy teaching practice. 


\section{Educere "Educare \\ Revista de EduCAČ̃̃o}

Programa de Pós-Graduação em Educação - Universidade Estadual do Oeste do Paraná

\section{SITUANDO O CONTEXTO DA INVESTIGAÇÃO}

Este estudo tem como objetivo: compreender como são mobilizados os saberes da prática alfabetizadora no cotidiano das professoras iniciantes. Nesse sentido, a questão norteadora que propusemos a investigar nesta pesquisa é saber: como são mobilizados os saberes da prática alfabetizadora no cotidiano das professoras iniciantes?

Trata-se de uma pesquisa de abordagem qualitativa, que se inscreve como um relato de experiência tecido no cotidiano da prática alfabetizadora de professoras iniciantes, que atuam nos anos iniciais do Ensino Fundamental.

A perspectiva teórico-epistemológica adotada nesta pesquisa são os "Estudos do Cotidiano", entrelaçando-se com a "Epistemologia da Complexidade" para a compreensão das narrativas expressas pelas interlocutoras participantes da pesquisa, colhidas através das "conversas" que foi o instrumento por nós escolhido, juntamente com as "observações" que foram registradas em gravações em áudio e em diário de pesquisa.

A presente investigação aconteceu no primeiro semestre de 2014 , e contou com a participação de três professoras iniciantes que atuam nos anos iniciais do Ensino Fundamental numa escola do sistema público na cidade de Caxias-MA.

Entre tantos projetos e desejos, emoções e obstáculos, experiências e concretizações, que se consubstanciavam em ações cotidianas, a prática alfabetizadora representava uma das mais presentes preocupações das professoras iniciantes, e que as impulsionavam à mobilização de saberes e fazeres que pudessem contribuir para alfabetizar as crianças, e assim, efetivar um trabalho didático, educativo e pedagógico, pautado nas habilidades de leitura e escrita que as fizessem progredir para outras etapas de ensino.

Quanto ao perfil das interlocutoras que participaram da pesquisa, são três professoras, formadas em Pedagogia, e que duas possuem especialização lato 


\section{Educere "Educare \\ Revista de EduCAČ̃̃o}

Programa de Pós-Graduação em Educação - Universidade Estadual do Oeste do Paraná

sensu em Gestão e Supervisão Escolar. Atuam na escola há dois anos, assim que iniciaram suas atividades educacionais e profissionais com contrato temporário, sujeito a renovação a cada ano.

Para respeitar os aspectos éticos e legais da pesquisa científica, não revelamos os nomes verdadeiros das pesquisadas, resguardando, portanto, suas identidades. Assim, utilizamos pseudônimos de flores, a saber: Margarida, Rosa e Íris.

Optamos por pesquisar professoras em início de carreira, porque nossas pesquisas e investigações tem contemplado a formação inicial e continuada de professores/as, e nos encontros que estabelecemos, nos defrontamos continuamente com algumas questões, dúvidas, ambiguidades entre outros elementos manifestados pelas nossas pesquisadas. Além do mais, muitos questionamentos e aprendizagens que construímos nos interessam e nos fazem refletir também como isso acontece com outros/as professores e professoras. E como as pesquisadas foram somente mulheres por ocuparem um maior número na docência, devido a uma construção histórica e cultural que nossa sociedade foi se consolidando ao longo do tempo, utilizamos o termo "professoras" no feminino neste texto.

Conversamos com as professoras interlocutoras da pesquisa, que as escolhemos devido estarem no início da carreira, ou seja, são professoras iniciantes aquelas mencionadas pela literatura como atuantes entre um período de 1 a 3 anos no magistério, segundo Marcelo Garcia (1999), Huberman (2000) e Tardif (2012).

Como a perspectiva teórico-epistemológica adotada por nós foram os Estudos do Cotidiano, que é uma corrente de pesquisa contra hegemônica, na qual o próprio pesquisador se envolve durante a investigação, no sentido de estar dentro, no contexto da prática e com os(as) interlocutores(as) da pesquisa, buscando captar as sutilezas, imprevisibilidades, os múltiplos saberes e práticas produzidos/criados pelos sujeitos, diferentemente do que concebe a ciência 


\section{Educere "Educare \\ ReVISTA DE EduCACÃ̃o}

Programa de Pós-Graduação em Educação - Universidade Estadual do Oeste do Paraná

clássica positivista e cartesiana que hierarquiza, delimita e oficializa o conhecimento para (de) uns em detrimento de outros, nos embebemos de pensadores estrangeiros, como Certeau (2012) e Santos (2006), enquanto no território brasileiro nos pautamos nas investigações tecidas por Oliveira (2012a; 2012b), Alves (2003), Ferraço (2007; 2008) e Oliveira; Sgarbi (2008). Assim, entendemos o cotidiano como: "[...] espaçotempo" da complexidade da vida social, na qual se inscreve toda produção de conhecimento e práticas científicas, sociais, grupais, individuais" (OLIVEIRA; SGARBI, 2008, p. 72).

Nesse sentido, entendemos o cotidiano como a produção de sentidos, de práticas e saberes que se consolidam nos múltiplos contextos de aprendizagem, de troca de informações e de valorização e construção da informação e do conhecimento, através do entrelaçamento de sabres e não-saberes que circulam entre os vários sujeitos e em várias dimensões da vida, da existência e da profissão.

O cotidiano se revela de mil maneiras; às vezes inusitado, imprevisivel, impactante, diferente, instável e até provocante. Esse mesmo cotidiano é o que desperta a construção do novo e a consolidação de proficuas e substantivas práticas, saberes e a tessitura da própria vida, em meio ao caráter repetitivo e rotineiro que a prática docente suscita em sua complexidade.

Segundo mostra Lacerda (2011, p. 60), "[...] são tantos os movimentos que se processam em cotidiano! Conversas, práticas, observações, registros...". Momentos esses, que muitas vezes não são vistos imediatamente, ou não são percebidos como situações de construções de aprendizagens, pelas professoras iniciantes em seus contextos de atuação e vivências estabelecidas cotidianamente.

Pesquisar no cotidiano é inventar e construir sentidos na produção do conhecimento científico, tão necessários nos dias de hoje, para o desenvolvimento da pesquisa, da educação e da formação dos sujeitos que vivenciam e tecem os mais diferenciados e múltiplos saberes e fazeres em seus contextos de atuação sociocultural, existencial, e consequentemente profissional. 


\section{Educere "Educare \\ Revista de EduCAČ̃̃o}

Programa de Pós-Graduação em Educação - Universidade Estadual do Oeste do Paraná

Quanto às conversas, enfatizamos que já foram utilizadas como técnicas de investigações científicas no âmbito educacional, na tese de Doutorado em Educação de Albuquerque (2010) defendida na Universidade Federal FluminenseUFF, na Dissertação de Mestrado em Educação de Morais (2015) e de Girardi (2012) estas últimas, ambas defendidas na Universidade Federal do Rio Grande do NorteUFRN, bem como nas práticas pedagógicas no ensino superior desenvolvidas no curso de Licenciatura em Geografia na Universidade Estadual do Rio Grande do Norte-UERN por Nascimento; Silva (2009).

Adotamos a concepção de González-Rey (2005) acerca das conversas. O autor denomina de conversação e que tem o mesmo sentido para o que estamos tratando neste texto. A acepção proposta de conversa é a de que esta:

[...] é um processo cujo objetivo é conduzir a pessoa estudada a campos significativos de sua experiência pessoal, os quais são capazes de envolvêla no sentido subjetivo dos diferentes espaços delimitadores de sua subjetividade individual (GONZÁLEZ-REY, 2005, p. 126).

Assim, é uma forma de acessar universos em que estão sendo produzidos sentidos subjetivos nas práticas pedagógicas cotidianas das professoras iniciantes, e que, por esse meio, possamos desvelar contextos não revelados por outros mecanismos, muitas vezes fechados e lineares.

A compreensão subjacente das conversas que empreendemos aqui, diz respeito a um processo de interação entre duas ou mais pessoas, na qual exista a compreensão dos enunciados proferidos na comunicação discursiva entre ambas, sem a determinação ou mesmo imposição de regras, hierarquias e modelos préestabelecidos do que possa ser conversado.

No que se refere a perspectiva que adotamos para compreender as narrativas das professoras, que fizemos alusão no início desse texto, que é a Epistemologia da Complexidade, entendemos que é por meio desta que conseguimos captar as múltiplas nuances e atravessamentos que são vivenciados, afetados e percorridos nesse cotidiano fugidio, diferente, imprevisível, caótico e mesmo complexo, no qual 


\section{Educere "Educare \\ ReVISTA DE EduCACÃ̃o \\ Programa de Pós-Graduação em Educação - Universidade Estadual do Oeste do Paraná}

se tecem uma infinidade de saberes pelos sujeitos ordinários, e que são essenciais à produção do conhecimento e dos saberes da experiência. Ao primarmos por esse paradigma, partimos do princípio de que:

[...] não "produz" nem "determina" a inteligibilidade. Pode somente incitar a estratégia/inteligência do sujeito pesquisador a considerar a complexidade da questão estudada. Incita a distinguir e fazer comunicar em vez de isolar e de separar, a reconhecer os traços singulares, originais, históricos do fenômeno em vez de liga-los pura e simplesmente a determinações ou leis gerais, a conceber a unidade/multiplicidade de toda entidade em vez de a homogeneizar em categorias separadas ou de a homogeneizar em indistinta totalidade. Incita a dar conta dos caracteres multidimensionais de toda realidade estudada (MORIN, 2010, p. 334).

Foi, esse paradigma ou epistemologia com o qual encontramos terreno fértil para compreender as narrativas das professoras iniciantes da pesquisa, e que mais se acentuou com os estudos do cotidiano.

Apresentamos a seguir as narrativas enunciadas pelas professoras pesquisadas, que foram tecidas em meio às conversas que estabelecemos no cotidiano escolar e buscamos fazer algumas discussões no tocante aos saberes da prática alfabetizadora, com o qual nos propusemos na temática deste artigo.

\section{OS SABERES DA PRÁTICA ALFABETIZADORA: CONVERSAS COM PROFESSORAS INICIANTES NO COTIDIANO ESCOLAR}

Os saberes mobilizados pelas professoras iniciantes não se restringem apenas aos saberes cognitivos, e adquiridos dentro da instituição escola, mas também fora deste contexto e com outros sujeitos, como os saberes que relacionam-se com os que aprenderam/aprendem: na formação inicial; nas experiências tidas na família na educação de seus filhos, sobrinhos, etc.; na igreja quando nas atividades propostas por esta instituição trabalhando os valores e aspectos comportamentais que devem ter e aprender as crianças; na formação continuada, em eventos na área da educação, nos encontros promovidos pela secretaria municipal de educação, em cursos de extensão, etc.; nas conversas 


\title{
Educere Educare \\ ReVISTA DE EduCACÃ̃o
}

Programa de Pós-Graduação em Educação - Universidade Estadual do Oeste do Paraná

tecidas com outros pares profissionais mostrando o que fazem e trocando experiências com estes; em viagens a outros lugares, que passam a conhecer culturas diferentes ampliando seu leque de saberes acerca da realidade que estão vivenciando e passando a compará-las a outras; na troca de experiências com outros profissionais quando vão até à escola em atividades pedagógicas e educativas propostas por esta; enfim, essa gama variada de lugares, sujeitos e experiências, potencializam o que as professoras iniciantes já possuem, e passam a somar-se ao seu universo de saberes complexificando-os cada vez mais, e permitindo a realização de uma prática pedagógica alfabetizadora mais plural, significativa e com a possibilidade de resolver questões que se apresentam de maneiras incertas, imprevisiveis e mesmo conflitivas no cotidiano de sua prática pedagógica. Assim, os saberes profissionais dos professores, como diz Tardif (2000), são plurais e heterogêneos. Buscando aprofundar melhor essa questão:

\begin{abstract}
Em primeiro lugar, eles [saberes] provêm de diversas fontes. Em seu trabalho, um professor se serve de sua cultura pessoal, que provém de sua história de vida e de sua cultura escolar anterior; ele também se apóia em certos conhecimentos disciplinares adquiridos na universidade, assim como em certos conhecimentos didáticos e pedagógicos oriundos de sua formação profissional; ele se apóia também naquilo que podemos chamar de conhecimentos curriculares veiculados pelos programas, guias e manuais escolares; ele se baseia em seu próprio saber ligado à experiência de trabalho, na experiência de certos professores e em tradições peculiares ao oficio de professor (TARDIF, 2000, p. 14).
\end{abstract}

De acordo com o exposto, entendemos que os saberes são plurais e que permitem a materialização dos fazeres. Assim, é preciso que as professoras iniciantes saibam primeiramente quais os saberes que podem ser mobilizados, considerando os elementos: "para que", "o que" e "como" no processo de ensino e aprendizagem, numa perspectiva da didática. Colocando esses questionamentos básicos, sua prática pedagógica passa a constituir-se com sentido e intencionalidade.

Alfabetizar é uma tarefa extremamente difícil de se realizar, sobretudo, quando não se tem muitas experiências vivenciadas com essa prática na educação 


\section{Educere "Educare \\ Revista de EduCAČ̃̃o}

Programa de Pós-Graduação em Educação - Universidade Estadual do Oeste do Paraná

escolar. Como as professoras iniciantes, participantes desta pesquisa atuam no $2^{\circ}$ ano do ensino fundamental dos anos iniciais, a maioria das suas atividades são direcionadas para o processo de alfabetização, daí a preocupação que sentem em mobilizar os saberes e fazeres necessários à prática alfabetizadora, para que possam, assim, contribuir qualitativamente, em sua prática pedagógica cotidiana, para o desenvolvimento das aprendizagens dos educandos.

Um dia um ditado de palavras... outro dia a leitura de um texto...outro ainda atividades para serem escritas e respondidas...um momento de acompanhamento individual com cada aluno trabalhando os jogos de palavras com a mesma família silábica, a criação de instrumentos didáticos e pedagógicos, uma atividade livre de invenção tecida pelas crianças, enfim, existem inúmeras atividades que as professoras iniciantes vão mobilizando ao longo do ano letivo e da vida profissional, dando ênfase à leitura, escrita e interpretação, ou seja, buscando mecanismos de potencializar a aprendizagem alfabética dos educandos, uma vez que estes precisam progredir na escolarização, e que, se não obtiverem êxito, do ponto de vista da análise das professoras, dificilmente poderão ser aprovados no ano. Tudo isso vai ao encontro do que reporta Perez $(2006$, p. 5) de que "[...] No processo de alfabetização, é fundamental a construção de espaços onde a criança possa escrever o que pensa, onde seja capaz de entender o que os outros escrevem e se fazer entender através da linguagem escrita". Por isso, as professoras buscavam continuamente perspectivas as mais variadas possiveis durante suas aulas, tendo em vista ser a alfabetização um processo nada fácil e que demandava esforços para se efetivar no seu desenvolvimento profissional, tendo em vista seu maior objetivo: a aprendizagem dos estudantes.

O acompanhamento que fomos tecendo no cotidiano da sala de aula, nos permitiu observar resultados exitosos e ao mesmo tempo surpreendentes no desenvolvimento das habilidades alfabéticas dos alunos, mas não somente nesta perspectiva cognitiva, como também comportamental, afetiva e valorativa das inúmeras questões e tentativas de aprendizagem que se processavam na sala de 


\section{Educere Educare \\ Revista de EduCAČ̃̃o}

Programa de Pós-Graduação em Educação - Universidade Estadual do Oeste do Paraná

aula, e mais especificamente nas relações interpessoais tecidas entre educando e docente, e das crianças entre si. Uma das professoras nos mostrou, através do seu relato, como percebia o contexto de aprendizagem dos seus educandos, da seguinte maneira: "Os meninos não sabiam muita coisa. Agora que estou alfabetizando eles" (Conversa com profa. Margarida, 2014).

Como não estávamos presente em sala de aula todos os dias com as professoras iniciantes, mas apenas alguns dias do mês durante a realização da pesquisa que se deu no ano de 2014, o fato de nós percebermos os avanços dos educandos no processo de alfabetização nos impactou mais fortemente, e então, íamos questionando, como acontecia essa concretização, que pra nós parecia bastante dificil, uma vez que quando iniciaram o ano letivo, as crianças chegaram com muitas dificuldades na escrita, na leitura e, consequentemente na interpretação do que era abordado pelas professoras nas aulas, ou quase nem sequer dominando muitas dessas habilidades, fruto de anos anteriores cursados, conforme relataram as professoras iniciantes, seja em detrimento de resquícios do $1^{\circ}$ ano que não conseguiram se alfabetizar, como também da falta de acompanhamento dos pais, e mesmo comprometimento das outras professoras, dando primazia para esse processo. O relato a seguir ilustra bem essa questão: "Acho que a dificuldade em as crianças não se alfabetizarem está no professor" (Conversa com profa. Margarida, 2014).

O fragmento do discurso acima mostra o fato das crianças não conseguirem trazer uma gama de saberes e conhecimentos básicos de leitura e escrita, como a professora esperava no $2^{\circ}$ ano do ensino fundamental, e que a criança está cursando.

Diante do exposto e tomando como princípio a fala da professora Margarida, entendemos que a culpa da falta de compreensão da leitura e escrita dos estudantes não está só na professora anterior, quando sabemos que a dificuldade em alfabetizar no tempo certo infelizmente é uma problemática mais ampla do sistema educativo brasileiro 


\section{Educere "Educare \\ Revista de EduCAČ̃̃o}

Programa de Pós-Graduação em Educação - Universidade Estadual do Oeste do Paraná

O mais relevante é que as professoras iniciantes organizavam detalhadamente o que iam mobilizar com os seus alunos no cotidiano de suas aulas, focalizando as atividades que pudessem explorar mais ainda as habilidades de alfabetização com as crianças. Dentre algumas das estratégias utilizadas pelas mesmas, cada uma tinha um caderno em que designavam didaticamente e pedagogicamente "para que fazer", "o que fazer" e "como fazer" determinadas atividades, explicitando então, os objetivos, os conteúdos, a metodologia, a avaliação, referências, enfim, os elementos que compõem um plano de aula e realizavam esse planejamento antes de iniciarem suas aulas.

Uma forte contribuição que vem dando cada vez mais substancialidade à prática pedagógica das professoras iniciantes, diz respeito ao programa Pacto Nacional Alfabetização na Idade Certa (PNAIC), que é “...um compromisso formal assumido pelos governos federal, do Distrito Federal, dos estados e municípios de assegurar que todas as crianças estejam alfabetizadas até os oito anos de idade, ao final do $3^{\circ}$ ano do ensino fundamental" (BRASIL, 2012). Portanto, trata-se de um programa com diretrizes educacionais criado pelo Ministério da Educação-MEC e que visa alfabetizar as crianças que ainda não obtiveram esse êxito na educação escolar fundamental, bem como visa o domínio das quatro operações básicas de matemática nesta etapa de ensino que contempla o respectivo programa.

Os encontros promovidos pelo PNAIC têm ajudado as professoras iniciantes a desenvolver mais e melhores atividades no processo de alfabetização, principalmente porque existem discussões de diversos assuntos e temáticas acerca da prática alfabetizadora, discutidas nas reuniões do programa, além de ter a interação com outros/as professores/as, também iniciantes e experientes, e que são oriundos de outras escolas, uma vez que acontecem encontros por polo, juntando, assim, as escolas que ficam próximas umas das outras, mas localizadas em bairros diferentes. Portanto, as outras professoras enfrentam contextos diferenciados em suas respectivas realidades, e o processo de troca de experiências, quando do encontro do PNAIC, permite a socialização do que desenvolveram, 


\title{
Educere Educare \\ Revista de EduCAČ̃̃o
}

Programa de Pós-Graduação em Educação - Universidade Estadual do Oeste do Paraná

quando planejaram anteriormente as atividades, e assim são avaliadas as mesmas que obtiveram ou não êxito no processo de ensino e aprendizagem, quanto ao desenvolvimento da alfabetização. Numa conversa que tivemos com uma das professoras ela chegou a nos revelar que:

\begin{abstract}
São poucos os que não sabem ler. Tem a questão da leitura; tem poucos que não conseguem ainda. Eles [alunos] já avançaram! Porque a gente trabalha com o Programa também: O PNAIC. Aí todo dia é isso, todo dia, tem que se trabalhar pra poder... ler. Aí, hoje eu trabalhei a questão da Matemática [...]. Ai as outras disciplinas a gente trabalha a questão da interdisciplinaridade, com cada gênero textual... (Conversa com profa. Rosa, 2014).
\end{abstract}

As professoras iniciantes tem reconhecido o PNAIC como um programa que não somente tem servido para ajudar no processo de alfabetização das crianças, mas para além dessa dimensão, em que vem fornecendo elementos fundamentais, fazendo-as aprenderem práticas e saberes novos, bem como a desenvolver suas reflexões no sentido de aperfeiçoar o que conheciam e que o programa veio reforçar suas práticas.

Buscando um ponto de vista da epistemologia da complexidade, entendemos que transitamos em vários espaços os quais constituem a consolidação de nossos conhecimentos. Assim, as professoras iniciantes aprendem os saberes da prática pedagógica em outros contextos de experiências cotidianas. O que nos faz perceber que "[...] O homem tem muitas dimensões e tudo o que descola desse complexo é mutilante, não só para o conhecimento mas, igualmente, para a ação" (MORIN, 2010 , p. 130). É, pois, nos inúmeros contextos onde se entranham que as professoras iniciantes retornam para o seu trabalho cotidiano, agindo sobre o seu objeto e sua realidade, ou seja, desenvolvendo o processo ensino e aprendizagem.

Ao mesmo tempo em que iam realizando suas aulas, as professoras teciam continuamente exemplos e comparações da evolução de seus educandos, elogiando-os quando apresentavam bom desempenho, mas ao mesmo tempo incentivando-os quando não estavam dispostos a participarem das atividades propostas por elas, embora a maioria das vezes as crianças se mostravam 


\section{Educere "Educare \\ Revista de EduCAČ̃̃o}

Programa de Pós-Graduação em Educação - Universidade Estadual do Oeste do Paraná

motivadas e participativas, salvaguardando algumas exceções, quanto a poucos momentos em que isso acontecia, e era apenas com algumas das crianças que apresentavam esse tipo de comportamento, muitas vezes fruto mesmo das metodologias utilizadas pelas professoras que não agradavam ou despertavam as crianças.

Alguns dos exemplos que as professoras iniciantes mostravam em suas aulas, quanto às suas práticas alfabetizadoras: pegavam o caderno de alguns educandos e iam folheando as atividades realizadas pelos pequeninos desde o começo do ano letivo, fazendo comparações de suas letras e a própria estética do caderno diante do início do ano letivo, comparando-o com a atualidade, percebendo até que ponto eles conseguiram avançar; pediam que as crianças lessem algumas atividades que elas (professoras) passavam, explorando sua linguagem e compreensão leitora; questionavam as crianças quando diziam determinadas frases, orações e textos, buscando captar os sentidos, as compreensões e entendimentos das crianças; solicitavam a participação dos educandos individualmente para responder as atividades no quadro, e todos ficavam apreensivos e se motivavam ainda mais, cada qual querendo participar; criavam momentos de práticas para que as crianças explorassem suas habilidades e criatividade, escrevendo o que quisessem e criando gênero epistolar e outros diferentes, orientados inicialmente pelas professoras, entre outras práticas.

E tudo isso acontecia muitas vezes colocando ênfase e explicações do que faziam para nós pesquisadores, ou seja, as professoras iniciantes tinham confiança e gostavam de partilhar o que conseguiram alcançar, fazer ou pensar em cada momento, tendo-nos como interlocutores daquele processo, nos ajudando, consequentemente durante a pesquisa.

Alfabetizar uma criança é um jogo de encanto, emoção, magia e sedução, que se manifestava a cada momento em que as professoras pesquisadas percebiam os avanços com seus educandos, e de igual medida isso nos afetava emocionalmente de forma positiva, nos deixando atônitos e felizes, principalmente quando nós 


\section{Educere Educare \\ RevisTA De EduCAC̄̃̃o}

Programa de Pós-Graduação em Educação - Universidade Estadual do Oeste do Paraná

percebíamos a emoção e orgulho das professoras quando obtinham retorno das crianças, ou seja, quando estas aprendiam. Essas conquistas mostravam a esperança que cada professora iniciante ia construindo no cotidiano de sua atuação profissional.

Todas as vezes em que nós estabelecíamos contato com o cotidiano escolar das professoras iniciantes, elas tinham algo diferente a nos contar, sempre movidas pelo interesse em desenvolver uma prática pedagógica qualitativa. Isso acontecia também quando moviam ações as quais não obtiveram sucesso e ficava com um desejo em realizar o que ainda não tinham cumprido. Uma das professoras deixou claro que:

Essa parada é prejudicial [pequeno recesso para acompanhar a copa do mundo, que aconteceu no primeiro semestre de 2014] porque prejudica os alunos, principalmente porque eles estão 'engatinhando' na leitura e como os pais não ajudam, acaba interrompendo o desenvolvimento que eles apresentam (Conversa com profa. Íris, 2014).

Outro exemplo refere-se ao fato das dificuldades econômicas que interferem em alguns aspectos no desenvolvimento da aprendizagem alfabetizadora das crianças, uma vez que quando os cadernos de algumas delas já não tinham mais folhas para irem desenvolvendo a escrita e outras atividades solicitadas pelas professoras, os pais não tinham condições para providenciarem em tempo hábil para as crianças acompanharem as aulas, e as professoras se sentiam na necessidade de resolver esta situação, abrindo mão do seu próprio salário para comprar materiais aos pequeninos, para então não interferir mais ainda em sua prática pedagógica alfabetizadora e protelar a aprendizagem das crianças. Segundo a professora Margarida: "Os pais não ajudam as crianças; a gente pede uma ajuda, por exemplo, para comprar algum material e eles nem sequer dão importância".

\section{(Conversa com profa. Margarida, 2014).}

Portanto, essa questão, acabava de certo modo atrapalhando o percurso contínuo das atividades pedagógicas, atrasando cada vez mais o que poderia fazer. Como se pode perceber, os alunos, são filhos e filhas de trabalhadores e necessitam 


\section{Educere Educare \\ Revista de EduCAČ̃̃o}

Programa de Pós-Graduação em Educação - Universidade Estadual do Oeste do Paraná

de alguns materiais escolares essenciais para o seu desenvolvimento, encontrando na escola, uma alternativa para superar suas limitações de variadas ordens.

Algo interessante nos chamava a atenção durante as aulas das professoras pesquisadas, não de todas, mas algumas de que: a maioria de seus educandos já no final do primeiro semestre de 2014, sabiam ler e escrever e até mesmo interpretar algumas situações que as mesmas propunham quando consideravam necessário. Porém, algumas crianças resistiam à participarem das atividades desenvolvidas, até que as professoras insistiam ou mesmo quando traziam algo diferente para as aulas, que elas despertavam e ficavam ansiosas para se mobilizarem diante do que havia proposto para ser feito.

Os fazeres mobilizados pelas professoras iniciantes aconteciam de acordo com as necessidades percebidas por elas. Quando observavam determinada criança com dificuldades de aprendizagem na leitura e na escrita, elas reforçavam o acompanhamento junto a cada uma, para que pudessem se igualar às demais, e assim não apresentarem maiores conflitos durante o processo de escolarização e mesmo para não obstaculizar sua progressão escolar. Assim, a professora Margarida, por exemplo, incentivava as crianças a fazerem leituras individualmente em sua mesa, problematizando o que liam, para que as mesmas se interrogassem e (re)pensassem se, de fato, era o que estava escrito naqueles papéis ou atividades propostas, até acertarem e aprenderem. A estes educandos que apresentam maiores dificuldades na leitura e escrita, reforçava também a sua participação na escrita no caderno, nas atividades para serem feitas em casa, bem como na participação no quadro escrevendo as respostas das tarefas desenvolvidas em cada dia. Um dos relatos mostra essa preocupação, de fazer com que as crianças pudessem ser alfabetizadas, por meio de atividades desenvolvidas pela professora:

Faço também muito ditado com eles; estimula a alfabetização. Faço atividades grupais [no caso do ditado] e individuais, pedindo para eles lerem pra mim, na minha mesa pra saber como estão na leitura (Conversa com profa. Margarida, 2014). 


\section{Educere "Educare \\ ReVISTA DE EduCAČ̃̃o}

Programa de Pós-Graduação em Educação - Universidade Estadual do Oeste do Paraná

Esses fazeres mobilizados eram os que as professoras iniciantes consideravam pertinentes para que as crianças pudessem construir e desenvolver aprendizagens no processo de alfabetização, embora houvessem outros que consideramos muito mais importantes, principalmente quando estimulavam as crianças nas criações que realizam cotidianamente, através das múltiplas atividades que exploravam sua criatividade e autonomia. Dessa forma, as professoras pesquisadas mostravam-se inquietas quanto ao que desenvolver, e mais ainda se preocupavam com o retorno que poderiam obter, ou seja, o feedback da sua prática alfabetizadora, daí mobilizavam saberes outros que pudessem extrapolar o livro didático e o quadro branco, como: a confecção de jogo de palavras; criação de convites que eram realizadas pelas crianças; criação de jogos educativos, etc. Enfim, as professoras partiam do principio de "[...] um saber que se desenvolve no horizonte do outro e em vista dele". (TARDIF \& GAUTHIER, 2001, p. 194), tendo em vista o que era mobilizado pelas professoras em consideração à realidade enfrentada no cotidiano escolar.

Entendemos essas práticas, como as táticas, que segundo Certeau (2012), se constroem em meio às imprevisibilidades, ao fortuito, ao rotineiro, ao estabelecido oficialmente, e que extrapolam as dimensões repetidoras e sempre habituais preconizadas pela escola, mais precisamente pelo currículo oficial.

A prática pedagógica de alfabetização, só pode acontecer com efetividade quando as professoras iniciantes sabem mobilizar corretamente os saberes essenciais ao processo de alfabetização em suas respectivas realidades, para conduzir, no plano dos fazeres o que tem a ver com os níveis das crianças, considerando a realidade sociocultural de que fazem parte, bem como os limites e possibilidades reais, no que se refere aos aspectos afetivos, cognitivos, sociais, culturais e motores, que caracterizam determinadas aprendizagens das mesmas na escolarização. Por isso:

No processo de alfabetização das crianças, é mais importante o clima que se cria em sala de aula para a aprendizagem da leitura e da escrita. Isto é o que denominamos ambiente alfabetizador. A leitura e a escrita podem ser 


\section{Educere "Educare \\ RevisTa de EduCAC̄̃o \\ Programa de Pós-Graduação em Educação - Universidade Estadual do Oeste do Paraná}

trabalhadas de forma lúdica e criativa. Brincando com a palavra, a criança incorpora-a à sua realidade e utiliza-se dela para expressar-se e comunicarse (PEREZ, 2006, p. 63).

Essa criatividade que desperta para a aprendizagem era estimulada pelas professoras iniciantes que criavam momentos, práticas e metodologias lúdicas, passando a promover facilidades para a aprendizagem alfabetizadora no cotidiano de sua prática, como chegamos a observar algumas vezes e que mencionamos algumas dessas experiências neste texto.

Em se tratando dos saberes da prática alfabetizadora, as professoras pesquisadas acionavam suas táticas, como também suas estratégias cotidianas (CERTEAU, 2012), para além do que se apresentava no seu universo existencial, extrapolando as regras e documentos oficiais da escola, embora, muitas vezes se preparavam antes de mobilizar qualquer saber ou fazer em sala de aula, e faziam isso nas horas de folga, em suas respectivas realidades, além de terem o tempo propiciado pelo planejamento que tinham com a coordenadora pedagógica da escola, como também nos encontros do PNAIC.

Os fazeres alfabetizadores das professoras iniciantes, eram relacionados com as experiências socializadas nos planejamentos da escola e do PNAIC; com o que aprenderam na formação inicial e está sendo potencializado na formação continuada; com as discussões, reflexões e estudos de casos desenvolvidos nos cursos de especialização, os quais fizeram (apenas duas das pesquisadas); com as próprias atividades desenvolvidas pela escola em outros espaços fora da sala de aula, e inclusive fora da escola; no acompanhamento da coordenadora do PNAIC em sua sala de aula, nas atividades cotidianas, buscando perceber o que estavam mobilizando, relacionados ao processo de alfabetização, muitas das quais as atividades eram as abordadas pelo programa, e então, após a observação desta coordenadora existia um momento de discussão e reflexão com as professoras iniciantes, para avaliarem o que estava bom ou o que precisava melhorar; enfim, uma série de atividades que iam sendo desencadeadas conforme o cotidiano 


\section{Educere "Educare \\ Revista de EduCAČ̃̃o}

Programa de Pós-Graduação em Educação - Universidade Estadual do Oeste do Paraná

propiciava, os quais se articulavam com o que as professoras projetavam antes de entrar na sala de aula.

Diante dos saberes e fazeres acima mencionados que foram sendo mobilizados pelas professoras iniciantes, nos faz entender que, por mais que saibamos, que possamos dominar muitos saberes, estes só serão importantes e só valerão a pena se soubermos comunicá-los, socializá-los a outros, que encontramse numa situação de aprendente.

De certo modo, os saberes alfabetizadores têm estreita relação com os fazeres, pois as professoras iniciantes buscam compreender, aprimorar e adquirir determinados saberes que ainda não sabem/conhecem, para mobilizar em sua prática, visando alfabetizar as crianças, para conseguirem avançar em outros conteúdos mais complexos, e mesmo compreender a dinâmica do processo de alfabetização, em que primeiro se trabalha os conteúdos elementares e que vão sendo abordados outros mais complexos posteriormente, e assim sucessivamente.

As professoras iniciantes se sentem acolhidas, agraciadas e lisonjeadas por estarem aprendendo saberes e práticas propiciadas pelo PNAIC. Consideram positivo esse programa que vem ajudando-as cada vez mais na constituição de suas identidades profissionais, com ênfase para o que mobilizam na prática alfabetizadora.

Algumas vezes nos deparamos com situações comparativas enunciadas pelas professoras iniciantes quanto a turma que lecionaram no ano anterior (2013) com relação a turma atual (2014). Elas percebem as dificuldades iniciais, como as crianças chegam, muitas vezes sem saberem uma letra, uma sílaba, quanto menos uma palavra, fazendo apenas rabiscos e garatujas, e sentem uma grande responsabilidade e compromisso que devem ter, do começo do ano letivo em diante, para alfabetizar essas crianças. Uma das professoras chegou a nos relatar que: "A minha turma esse ano nem se compara a do ano passado. Está mais mista. A do ano passado era uma maravilha" (Conversa com profa. Rosa, 2014). 


\section{Educere Educare \\ ReVISTA DE EduCACÃ̃o}

Programa de Pós-Graduação em Educação - Universidade Estadual do Oeste do Paraná

Diante do exposto, há algo a ser problematizado: a professora pensa que o melhor é ter uma turma homogênea. Essa realidade (turmas homogéneas não existem) ela tem um desafio maior que é superar este seu ideal para depois trabalhar com as crianças reais. Como mobilizar este saber? Acreditamos que o confronto com as múltiplas personalidades e modos de ser e estar dos seus educandos, foi mostrando a própria professora as necessidades de mobilizar os saberes necessários a sua prática alfabetizadora, como pudemos observar no seu cotidiano que passou: a realizar aulas passeio; a levar filmes e vídeos; a construir quebra-cabeças e jogos de palavras; a construir jogos educativos, etc. Criações estas focando a aprendizagem da alfabetização e o respeito à diversidade de aprendizagens e ritmos no contexto do ensino.

Por isso, as professoras iniciantes passavam a buscar uma infinidade de saberes e fazeres, em vários contextos, com diferentes sujeitos e lugares, para então, cumprir não somente a uma exigência institucional, mas para realizar suas próprias aulas, com entusiasmo, motivação e prazer, enfim, para "dar conta do recado" como as mesmas procuravam concretizar. Situação parecida encontramos também com uma pesquisa desenvolvida com professoras iniciantes desenvolvida por Corsi (2005, p. 14) em que: "Os questionamentos sobre a prática, a comparação com as experiências anteriores, a reflexão sobre as atitudes tomadas diante das situações, revelam a preocupação das professoras com o próprio desenvolvimento profissional". Ou seja, sempre em meio ao aprender da profissão, buscavam acionar suas táticas que permitem a tessitura de saberes, e assim, a consequente viabilização da aprendizagem dos seus alunos, mobilizando os saberes e fazeres necessários para a sua prática alfabetizadora. O cotidiano, portanto, ganha sentido e outras características quando elas inventavam outras práticas diante das existentes. 


\section{Educere "Educare \\ Revista de EduCAČ̃̃o}

Programa de Pós-Graduação em Educação - Universidade Estadual do Oeste do Paraná

\section{TECENDO ALGUMAS CONSIDERAÇÕES}

Muito do que mobilizam, como as experiências mencionadas neste artigo, criadas pelas professoras iniciantes, buscavam focalizar a alfabetização e mobilizar os saberes numa perspectiva emancipatória (OLIVEIRA, 2012a), traduzidas na valorização dos saberes dos educandos, dos demais sujeitos tanto os que fazem parte do processo de escolarização como de outros contextos, e na tessitura de saberes oriundos não apenas do conhecimento, os pedagógicos e relativos à formação científica, mas do senso comum, da cultura, da religião, da pedagogia, das relações humanas, da vida mesmo cotidiana e das várias outras áreas do conhecimento e da realidade circundante.

Assim, ao valorizar as diferenças dos sujeitos, com suas singularidades acerca da aprendizagem alfabetizadora, as professoras iniciantes estão também sabendo valorizar o que muitas vezes se encontra invisibilizado pelas práticas hegemônicas e que tem ficado à margem da sociedade (SANTOS, 2006), no que se refere a educação, ao ensino e a ciência. Dessa forma, as professoras iniciantes encontram outras formas e possibilidades de realizar suas aulas, dando credibilidade aos saberes e fazeres que potencializam suas práticas alfabetizadoras. Trata-se de encontrar significados pedagógicos e educativos em outras ações que são fundamentais para que as crianças possam aprender a ler e a escrever, em suma, se alfabetizarem, e que as professoras se encarregam dessa responsabilidade mobilizando os saberes que consideram pertinentes e possam fazer a diferença na vida de seus educandos.

Percebemos que um dos fatores que se apresentaram fortemente na busca de mobilização de saberes e saberesfazeres pelas professoras iniciantes em sua prática alfabetizadora se refere ao fato de possuir pouca experiência na profissão, como também dúvidas que permeiam sua subjetividade, quanto ao que mobilizar, como e de que forma, para assim, atender tanto as exigências institucionais como 


\section{Educere Educare \\ ReVISTA DE EduCACÃ̃o}

Programa de Pós-Graduação em Educação - Universidade Estadual do Oeste do Paraná

também fazer com que, de fato, as crianças possam se desenvolver, e, por conseguinte perceber se o trabalho que estão realizando, faz sentido, e qual o sentido que tem para elas próprias.

É preciso ressaltar que, para mobilizar saberes na prática alfabetizadora e para além desta, é preciso pesquisar, buscar mecanismos e estratégias que venham a possibilitar a concretização dessas duas dimensões na prática pedagógica cotidiana. Além disso, a qualidade dos saberes e saberesfazeres, bem como o resultado destes, serão percebidos pela complexidade de interações que se estabelecem, ou seja, buscá-los em vários lugares, com diferentes sujeitos e em inúmeras fontes: pedagógicas, científicas, culturais, sociais, religiosas, tecnológicas, eruditas, do senso comum etc., o que reporta para a variedade de saberes e saberesfazeres mobilizados; bem como o entrelaçamento dos saberes e o como estes podem ser construídos e desenvolvidos no cotidiano da prática pedagógica, o que repercutirá na aprendizagem ou não das crianças.

A pesquisa nos mostrou ainda que o programa PNAIC tem sido um "divisor de águas" na vida das professoras iniciantes, principalmente porque quando iniciaram profissionalmente já foram se adequando ao programa concomitantemente, o que passou a ajudá-las em sua prática alfabetizadora trazendo alguns elementos fundamentais para a sua prática pedagógica.

\section{NOTAS}

${ }^{1}$ Estética da escrita que aprendemos com Nilda Alves (2003) em que a junção de palavras é uma forma de inventar, produzir e criar outras tantas palavras para além da reprodução do conhecimento. Assim os demais estudiosos do cotidiano também utilizam duas ou mais palavras juntas para dar outros sentidos diferentes à produção da ciência. Neste texto primamos por esta forma de escrita. 


\section{Educere Educare \\ ReVISTA DE EDUCACÃ̃o}

Programa de Pós-Graduação em Educação - Universidade Estadual do Oeste do Paraná

\section{REFERÊNCIAS}

ALBUQUERQUE, Andréa Serpa. Quem são os outros na/da avaliação? caminhos possiveis para uma prática dialógica. Tese (Doutorado em Educação) Universidade Federal Fluminense, Niterói, 2010.

ALVES, Nilda. Cultura e cotidiano escolar. Revista brasileira de educação. Maio/Jun/Jul/Ago 2003 N²3.

BRASIL. Pacto Nacional pela Alfabetização na Idade Certa. Brasília: Ministério da educação, 2012. Disponivel em: <http://pacto.mec.gov.br/ >. Acesso: $17 /$ set. $/ 2015$.

CERTEAU, Michel de. A invenção do cotidiano: 1. artes de fazer. 19. ed. Tradução de Ephraim Ferreira Alves. Petrópolis, RJ: Vozes, 2012.

CORSI, Adriana Maria. Professoras iniciantes: situações dificeis enfrentadas no início da prática docente no ensino fundamental. In: 28 ${ }^{\mathbf{a}}$. Reunião Anual da ANPED, Caxambu, 2005.

FERRAÇO, Carlos Eduardo. Os sujeitos das escolas e a complexidade de seus fazeressaberes: fragmentos das redes tecidas em pesquisas com o cotidiano. In.: GARCIA, R. L.; ZACCUR, E. (Orgs.). Cotidiano e diferentes saberes. Rio de Janeiro: DP\&A, 2006.

. Pesquisa com o cotidiano. Educação e Sociedade, Campinas, vol. 28, n. 98, p. 73-95, jan./abr. 2007.

Currículo, formação continuada de professores e cotidiano escolar: fragmentos de complexidade das redes vividas. In.: FERRAÇO, C. E. (Org.). Cotidiano escolar, formação de professores(as) e curriculo. 2. ed. São Paulo: Cortez, 2008.

GARCIA, Regina Leite; ALVES, Nilda. Sobre formação de professores e professoras: questões curriculares. In.: LIBÂNEO, José Carlos; ALVES, Nilda (Orgs.). Temas de pedagogia: diálogos entre didática e currículo. São Paulo: Cortez, 2012.

GIRARDI, Fabiola Fontenele. A escola sob o olhar da familia: relações que se compreendem e se praticam no cotidiano. Dissertação (Mestrado em Educação), Universidade Federal do Rio Grande do Norte, 2012. 


\section{Educere Educare \\ RevisTA De EduCAC̄̃̃o}

Programa de Pós-Graduação em Educação - Universidade Estadual do Oeste do Paraná

GONZÁlEZ REY, Fernando. Pesquisa qualitativa e subjetividade: os processos de construção da informação. Tradução Marcel Aristides Ferrada Silva. São Paulo: Pioneira Thomson Learning, 2005.

HUBERMAN, Michäel. O ciclo de vida profissional dos professores. In.: NÓVOA, António (Org.). Vidas de professores. 2. ed. Porto: Porto editora: 2000.

LACERDA, Mitsi Pinheiro de. Redes de cooperação e solidariedade em cotidiano escolar. Revista educação em questão, Natal, v. 40, n.26, p. 48-68, jan./jun. 2011.

MARCELO GARCIA, Carlos. Formação de professores: para uma mudança educativa. Porto: Porto Editora: 1999.

MORAIS, Joelson de Sousa. A prática pedagógica no cotidiano de professoras iniciantes: tramas e desafios do aprender a ensinar. Dissertação (Mestrado em Educação), Universidade Federal do Rio Grande do Norte, Natal, 2015.

MORIN, Edgar. Ciência com consciência. Tradução de Maria D. Alexandre e Maria Alice Sampaio Dória. Ed. revista e modificada pelo autor. 14. ed. Rio de Janeiro: Bertrand Brasil, 2010.

NASCIMENTO, Maria Anezilany Gomes; SILVA, Cícero Nilton Moreira da. Rodas de conversa e oficinas temáticas: experiências metodológicas de ensino-aprendizagem em Geografia. In: Anais do $\mathbf{1 0}^{\circ}$ Encontro Nacional de Prática de Ensino de Geografia, Porto Alegre, 2009. Disponivel em: $<$ http://www.agb.org.br/XENPEG/artigos/Poster/P\%20\%2836\%29.pdf>. Acesso: $11 /$ março/2015.

OLIVEIRA, Inês Barbosa de. O currículo como criação cotidiana. Petrópolis, RJ: DP et Alii; Rio de Janeiro: FAPERJ, 2012a.

OLIVEIRA, Inês Barbosa de. Aprendizagemensino de qualidade nas escolas: a produção de conhecimento em didática e em currículo pelos praticantespensantes nos/dos cotidianos. In.: ALMEIDA, M. I. de et al. Políticas educacionais e impactos na escola e na sala de aula. Araraquara, SP: Junqueira\&Marin, 2012b.

OLIVEIRA, Inês Barbosa de; SGARBI, Paulo. Estudos do cotidiano e educação. Belo Horizonte: Autêntica Editora, 2008. (Coleção temas e educação).

PEREZ, Carmen Lúcia Vidal. O prazer de descobrir e conhecer. In.: GARCIA, Regina Leite (Org.). Alfabetização dos alunos das classes populares: ainda um desafio. 6. ed. São Paulo: Cortez, 2006. (Coleção Questões da Nossa Época; v. 6). 


\section{Educere Educare \\ RevisTA De EduCAC̄̃o}

Programa de Pós-Graduação em Educação - Universidade Estadual do Oeste do Paraná

SANTOS, Boaventura de Sousa. Para uma sociologia das ausências e uma sociologia das emergências. In.: (Org.). Conhecimento prudente para uma vida decente: um discurso sobre as ciências revisitado. 2. ed. São Paulo: Cortez, 2006.

TARDIF, Maurice. Saberes profissionais dos professores e conhecimentos universitários: elementos para uma epistemologia da prática profissional dos professores e suas consequências em relação à formação para o magistério. Revista brasileira de educação. $\mathrm{N}^{\circ} 13$, Jan/Fev/Mar/Abr, 2000.

TARDIF, Maurice; GAUTHIER, Clermont. O professor como "ator racional": que racionalidade, que saber, que julgamento? In.: PERRENOUD, Philippe et al Formando professores profissionais: Quais estratégias? Quais competências? Trad. Fátima Murad e Eunice Gruman. 2.ed. rev. Porto Alegre: Artmed, 2001.

Recebido em: 10/02/2018

Aprovado em: 10/10/2018 